Chemistry and Technology of Fuels and Oils, Vol. 42, No.3, 2006

\title{
RESEARCH
}

\section{RHEOLOGICAL PROPERTIES OF CRUDE OILS WITH A HIGH RESIN AND ASPHALTENE CONTENT. Effect of an Electromagnetic Field and Modifiers}

\author{
R. N. Shiryaeva, F. Kh. Kudasheva, R. N. Gimaev, \\ and Ch. Kh. Sagitova
}

UDC 665.61.085.6:543.422.4

The rheological properties of crude oils from the Kuchukov field were investigated at $20-70^{\circ} \mathrm{C}$ in the presence of surfactants and after treatment with a high-frequency electromagnetic field. The viscosity of crude from one field is a function of the resin and asphaltene content. Addition of ethylene glycol diglycidyl ether improves the rheological characteristics.

An increasing number of fields with high-viscosity crude is being exploited. The anomalies of the rheological properties of these crudes caused by a high resin and asphaltene (RA) wax content raises important difficulties in shipping them to refineries. Use of depressant additives [1,2], SF [3-5], and fields [6-8] is the most effective and efficient method of decreasing the viscosity of crude oil and increase the carrying capacity of pipelines.

We investigated the rheological properties of crudes from wells 69 and 719 in the Kuchukov field in Tatarstan and the effect of SF and a high-frequency electromagnetic (HFEM) field on the viscosity of these crudes during shipment. The physicochemical properties of the crudes are reported in Table 1. The crude from well 719 contained more resins and asphaltenes than the crude from well 69.

The viscosity of the crudes was determined on a Rheotest-2 rotary viscometer at shear rates from 3 to $1312 \mathrm{sec}^{-1}$ in the temperature range from 20 to $70^{\circ} \mathrm{C}$. The crude was thermostated at this temperature for $30 \mathrm{~min}$. Oligoisobutylene, OIB, with a molecular weight of $1500 \mathrm{~g} / \mathrm{mole}$, diphenylpropane diglycidyl ether ED-20 (320-430 g/mole), and ethylene glycol diglycidyl ether, DEG (240-260 g/mole) were added as SF in a concentration of up to $0.5 \mathrm{wt}$. \%. The crudes were exposed to the HFEM field in a $2.5 \mathrm{~kW}$ HF unit with a frequency of $13.56 \mathrm{MHz}$ for $10 \mathrm{~min}$.

Bashkir State University. Translated from Khimiya i Tekhnologiya Topliv i Masel, No. 3, pp. 34 - 35, May - June, 2006. 
Table 1

\begin{tabular}{|c|c|c|}
\hline \multirow{2}{*}{ Indexes } & \multicolumn{2}{|c|}{ Kuchukov crude } \\
\hline & well 69 & well 719 \\
\hline Density at $20^{\circ} \mathrm{C}, \mathrm{kg} / \mathrm{m}^{3}$ & 956.4 & 1005.7 \\
\hline Carbon residue, wt. \% & 7.9 & 10.9 \\
\hline \multicolumn{3}{|l|}{ Content, wt. \% } \\
\hline wax * & 1 & 1.2 \\
\hline sulfur & 4.9 & 3.8 \\
\hline water & 0.7 & 23 \\
\hline \multicolumn{3}{|l|}{ Group chemical composition, wt. $\%$} \\
\hline \multicolumn{3}{|l|}{ hydrocarbons } \\
\hline paraffins and naphthenes & 16.9 & 14.6 \\
\hline aromatics & 63.3 & 59.9 \\
\hline monocyclic & 11.8 & 9.3 \\
\hline bicyclic & 9.8 & 8.7 \\
\hline polycyclic & 41.7 & 41.9 \\
\hline \multicolumn{3}{|l|}{ resins } \\
\hline benzene & 7.6 & 9.8 \\
\hline alcohol and benzene & 9.6 & 12.3 \\
\hline asphaltenes & 2.6 & 3.4 \\
\hline Note. $\quad *$ Determined by the $\mathrm{x}$-ray structural method & & \\
\hline
\end{tabular}

Table 2

\begin{tabular}{|c|c|c|c|c|}
\hline \multirow{2}{*}{ Kuchukov crude } & \multicolumn{4}{|c|}{ Viscosity, $\mathrm{mPa} \cdot \mathrm{sec}$} \\
\hline & $20^{\circ} \mathrm{C}$ & $30^{\circ} \mathrm{C}$ & $40^{\circ} \mathrm{C}$ & $50^{\circ} \mathrm{C}$ \\
\hline \multicolumn{5}{|l|}{ From well 69} \\
\hline initial & 1272 & 504 & 132 & 44 \\
\hline \multicolumn{5}{|l|}{ with $0.5 \%$ SF } \\
\hline OIB & 910 & 493 & 143 & 42 \\
\hline DEG & 952 & 395 & 88 & 11 \\
\hline ED-20 & 1162 & 504 & 153 & 33 \\
\hline after treatment with HFEM field & 987 & 395 & 110 & 44 \\
\hline \multicolumn{5}{|l|}{ From well 719} \\
\hline initial & 1031 & 351 & 88 & 22 \\
\hline \multicolumn{5}{|l|}{ with $0.5 \%$ SF } \\
\hline OIB & 1119 & 439 & 132 & 22 \\
\hline DEG & 940 & 351 & 44 & 9 \\
\hline ED-20 & 1469 & 570 & 175 & 97 \\
\hline after treatment with HFEM field & 1293 & 504 & 153 & 50 \\
\hline
\end{tabular}




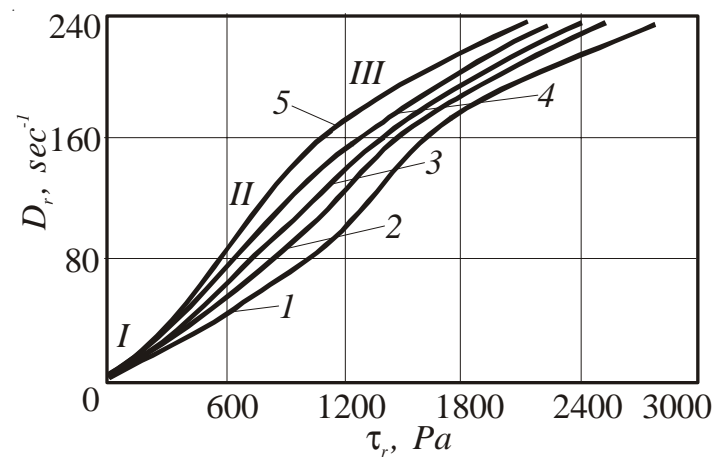

Fig. 1. Shear rate $D_{r}$ vs. shear stress $\tau_{r}$ at $20^{\circ} \mathrm{C}$ for crude from well 69: 1) initial; 2) after treatment with HFEM field; 3) with $0.1 \%$ Ed-20; 4) with $0.1 \%$ OIB; 5) with $0.1 \%$ DEG.

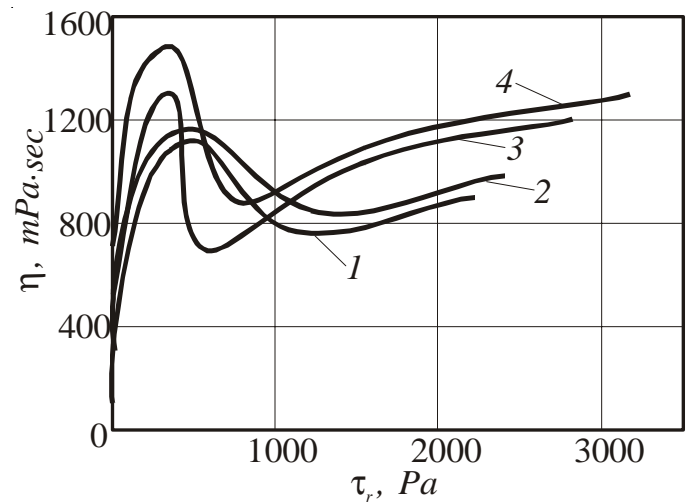

Fig. 2. Viscosity $\eta$ vs. shear stress $\tau_{r}$ at $20^{\circ} \mathrm{C}$ for crude from well 719: 1) initial;

2) with $0.5 \%$ OIB; 3) after treatment with HFEM field; 4) with 0.5\% ED-20.

The shear rate as a function of the shear stress for crude from well 69 is shown in Fig. 1. This curve has three characteristic segments. Segment $I$ corresponds to flow of the crude at low shear rates with almost no perturbation of the structure (appearance of creep), segment II corresponds to viscoplastic flow when shear stress of some value $\tau_{r}$ is attained, and segment $I I I$ corresponds to flow of crude at high shear stresses, where the structure is totally destroyed and the crude exhibits the properties of a Newtonian fluid.

The complex dependence of the viscosity on the external effect emphasizes a specific feature of the behavior of crudes with a high SF content. A positive viscosity peak at comparatively small shear stresses was characteristic of the crude from well 719 (Fig. 2). At low shear rates (up to $50 \mathrm{sec}^{-1}$ ), the viscosity of the crude and its compositions increases, probably due to phase transitions in the asphaltene particles.

In the phase transition, the surface energy of the asphaltene particles changes and the probability of their adhesion in larger aggregates increases, manifested by an increase in the viscosity of the SF-containing medium. With a further increase in the shear rate, the aggregates formed decompose and the viscosity of the system decreases. These features were also characteristic of the crude from well 69.

The SF and HFEM field affect the viscosity of the crudes differently (Table 2). The viscosity of the crude from well 69 decreased after addition of SF or treatment with the HFEM field. DEG had the greatest modifying effect. The viscosity of the crude from well 719 increased significantly after electromagnetic treatment. The resinous components of the crude were probably partially polarized and formed larger associates. As a consequence, 
the difference in the rheological properties of samples of Kuchukov crudes are due to their different chemical composition.

It follows from the results that use of a HFEM field to improve the rheological properties of crudes with a high SF content is not always expedient. DEG - ethylene glycol diglycidyl ether - is the most effective for these purposes.

\section{REFERENCES}

1. A. G. Akhmadeev, M. A. Safin, and E. V. Radionova, Transport Podgotovka Nefti, No. 3, 83-84 (2002).

2. S. S. Kozhabekov, V. B. Sigitov, and A. G. Didukh, Ibid., No. 2, 82-84 (2003).

3. R. F. Khamidullin, O. N. Shibaeva, and F. F. Khamidullin, Neft. Kozyaistvo, No. 2, 56-57 (2003).

4. O. G. Novozhilova, Le Khaang Lan, and V. N. Matveenko, Ibid., No. 10, $56-57$ (1990).

5. I. A. Khairullin, A. A. Rafikov, and V. G. Kozin, Transport Podgotovka Nefti, No. 1, 69-70 (2002).

6. N. A. Pivovarova, F. G. Unger, and B. P. Tumanyan, Khim. Tekhnol. Topl. Masel, No. 6, 30-32 (2002).

7. L. A. Kovaleva and F. S. Khismatullina, Izv. Vyssh. Uchebn. Zaved., Ser. Neft' Gaz, No. 1, 35-40 (2003).

8. Yu. V. Loskutova and N. V. Yudina, Neftekhimiya, 44, No. 1, 63-67 (2004). 